\title{
Quantitative Determination of Urinary Delta-Aminolevulinic Acid as an Index of Lead Exposure by High- Performance Liquid Chromatography
}

\author{
Key words: Delta-aminolevulinic acid-ALA pyrrole-Lead exposure-High-per- \\ formance liquid chromatography
}

Derangement in heme synthesis is the first adverse effect of an increasing lead burden. Inhibition of delta-aminolevulinic acid (ALA) dehydratase produces an accumulation of ALA in tissues and consequently causes its excretion in urine. ${ }^{1)}$

Previous colorimetric methods for the determination of urinary $\mathrm{ALA}^{2)}$ depended on purification of ALA by ion-exchange chromatography, which was timeconsuming when applied to many urine specimens. Wada et al. (1962) ${ }^{3)}$ described a colorimetric method for urinary ALA. In this method, ALA pyrrole produced by condensation of ALA with ethylacetoacetate was made to react with dimethyl amino benzaldehyde (DAB) which was then extracted with chloroform and measured by spectrophotometry. Tomokuni and Ogata (1972) ${ }^{4}$ reported an improved assay method for ALA, in which ALA pyrrole was produced by condensation of urinary ALA with ethylacetoacetate, and was extracted with ethylacetate. Thereafter, ALA pyrrole in the ethylacetate layer was made to react with DAB and the colored product was determined by spectrophotometry. Tomokuni et al. $(1985)^{5)}$ recommended the use of methylacetoacetate instead of ethylacetoacetate.

In the present study, an attempt was made to determine ALA pyrrole formed from urinary ALA by HPLC, in order to replace the colorimetric method as a specific and simple assay method for urinary ALA.

Reagents

All reagents used were of analytical grade from Wako Pure Chemical Industries Ltd. (Osaka, Japan), except for delta-aminolevulinic acid hydrochloride, which was from Sigma Chem. Co. (St. Louis, U.S.A.).

Urine Specimens

Specimens were obtained from healthy men not exposed to lead and from workers exposed to lead in shipyards.

Pretreatment of Urine

For determination by HPLC, $1.0 \mathrm{ml}$ of urine was pipetted into a $10 \mathrm{ml}$ glass-stoppered tube. Then $0.2 \mathrm{ml}$ of $60 \%$ acetic acid solution and $2 \mathrm{ml}$ of n-butanol were added. The added n-butanol was thoroughly mixed by vigorous shaking. Interfering substances were thus removed in the n-butanol layer. After allowing the urine mixture to stand for a while, $0.5 \mathrm{ml}$ of the aqueous phase was pipetted into a test tube, and $0.5 \mathrm{ml}$ of $1 \mathrm{M}$ sodium phosphate buffer ( $\mathrm{pH}$ 
6.8) and $0.1 \mathrm{ml}$ of methylacetoacetate were added successively. The tube was heated in a boiling water bath for $10 \mathrm{~min}$. After cooling, $10 \mu \mathrm{l}$ of the solution containing ALA-pyrrole was injected into a HPLC. An ALA standard and blank (water) were treated in the same way.

For determination of mass spectra, ALA pyrrole was produced by condensation of authentic ALA with methylacetoacetate as described above ${ }^{2)}$ and extracted with ethylacetate. The extract was dried using a rotary evaporator and ALA pyrrole in the residue was dissolved in methanol and injected into a mass spectrometer.

\section{Chromatographic Procedure}

An automated high-performance liquid chromatograph (Toyo Soda Co., Japan) with a $4.0-\mathrm{mm}$ (ID) $\times 150-\mathrm{mm}$ stainless steel column packed with octadecyl silanized 5- $\mu \mathrm{m}$ silica gel (TSK gel, Toyo Soda Co., Japan) and a UV detector at a wavelength of $260 \mathrm{~nm}$ was used throughout this investigation. A mixed solution of acetonitrile/ $50 \mathrm{mM} \mathrm{KH}_{2} \mathrm{PO}_{4}$ (adjusted to $\mathrm{pH} 2.5$ with a 0.001 volume of $85 \mathrm{~g} / \mathrm{dl}_{3} \mathrm{HO}_{4}$ ) at $20 / 80$ by volume was used as a favorable mobile phase for the separation of ALA. The flow rate was $1.2 \mathrm{ml} / \mathrm{min}$, the pressure produced was $60 \mathrm{~kg} / \mathrm{cm}^{2}$ and the column temperature was about $25^{\circ} \mathrm{C}$.

Mass Spectrometry

A Shimazu LKB-9000 mass spectrometer equipped with an electron ionization source was employed. The mass spectra were recorded by a direct inlet system. Conditions: Ion source temperature was $250^{\circ} \mathrm{C}$, electron energy was $70 \mathrm{eV}$ and source pressure reading was $10^{-6}$ torr.

High-performance Liquid Chromatograms of Authentic Specimens and Urine Specimens

ALA pyrrole was produced by condensation of authentic ALA with methylacetoacetate and was applied to the HPLC.

The chromatograms showed that ALA pyrrole was well separated from the other urinary compounds and eluted within about $20 \mathrm{~min}$ after injection (Fig. 1-A).

Chromatograms of urine specimens from the subjects not exposed to lead and workers exposed to lead are shown in Figs. 1-B and 1-C.

Calibration Curves of ALA in Water and in Urine

Standard solutions of ALA ranging from 2-20 mg/l were prepared. Each solution was mixed with an equal volume of water or control urine. After ALA pyrrole was produced by the method described above, the solution was iniected directly into the HPLC.

Figure 2 shows the linear relationship obtained between the peak height and ALA concentration. The calibration curve of ALA in urine paralleled with that of ALA in water. The displacement of the line for urine from the line for water was due to the ALA normally present in the urine of subjects non-occupationally exposed to lead.

Comparison of Urinary ALA Concentration Measured by HPLC and Colorimetry 

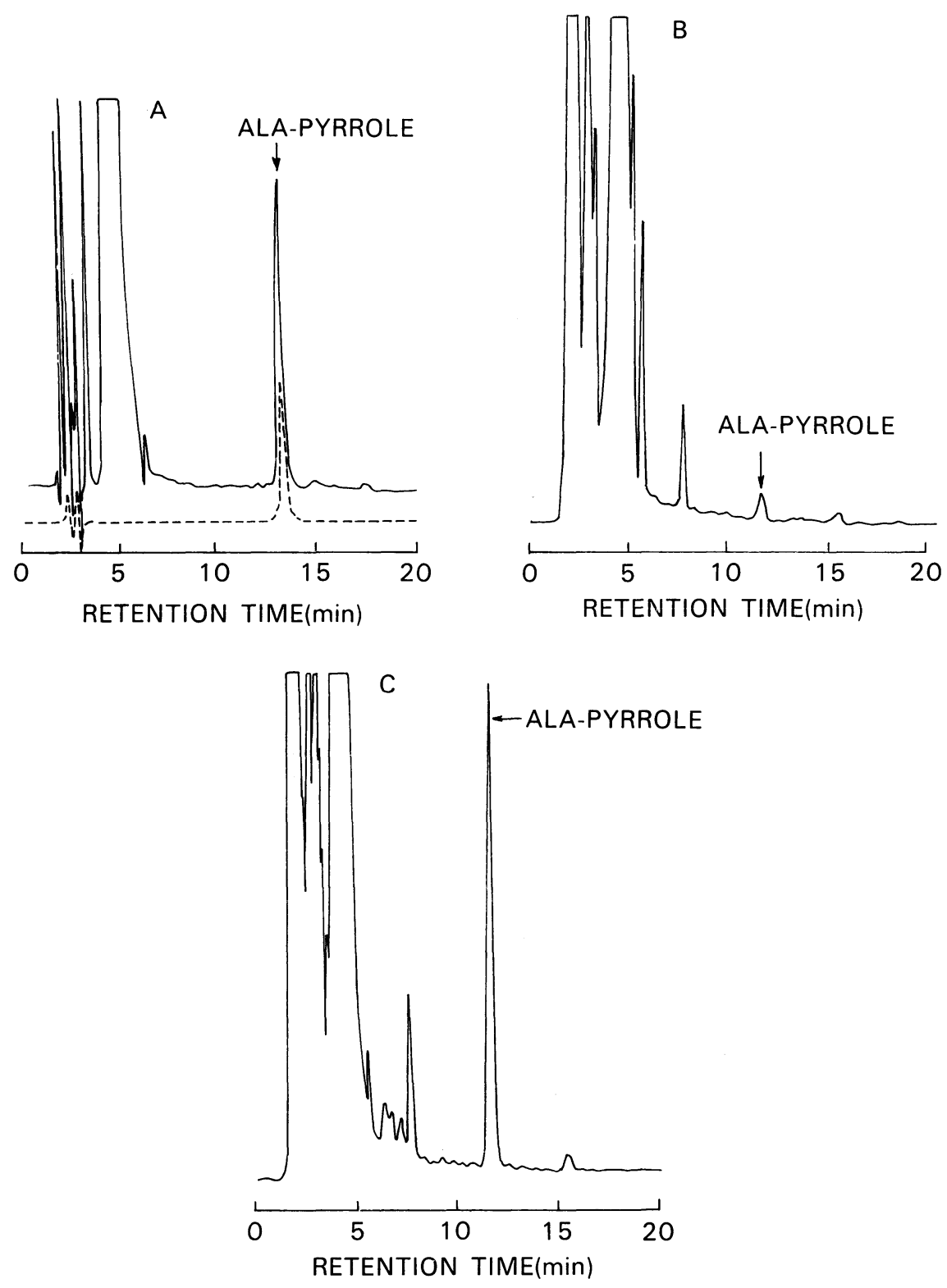

Fig. 1. High-performance liquid chromatograms of ALA pyrrole. A ; ALA pyrrole specimens. Solid line indicates ALA pyrrole produced from condensation of authentic ALA and methylacetoacetate. Dotted line, ALA pyrrole purified by the method described in this paper and submitted to mass spectrography. B ; urine from subjects not exposed to lead. $C$; urine of workers exposed to lead. 


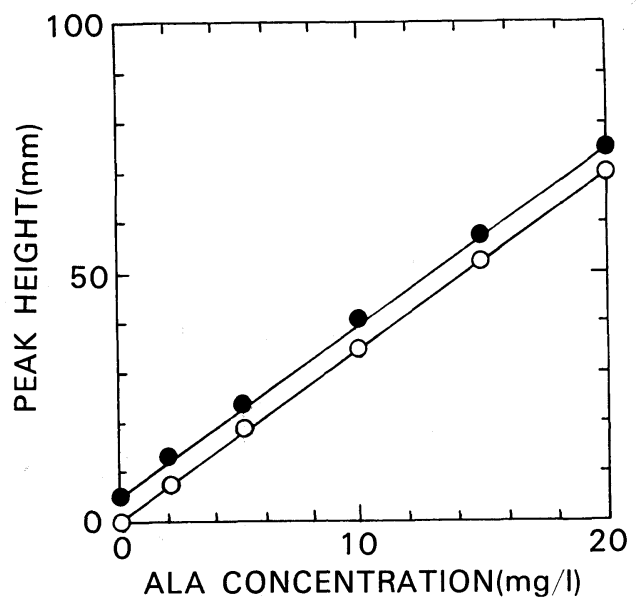

Fig. 2. Calibration curves of ALA for HPLC in water $(-\bigcirc-)$ and in urine $\left(-\mathrm{O}_{-}\right.$.

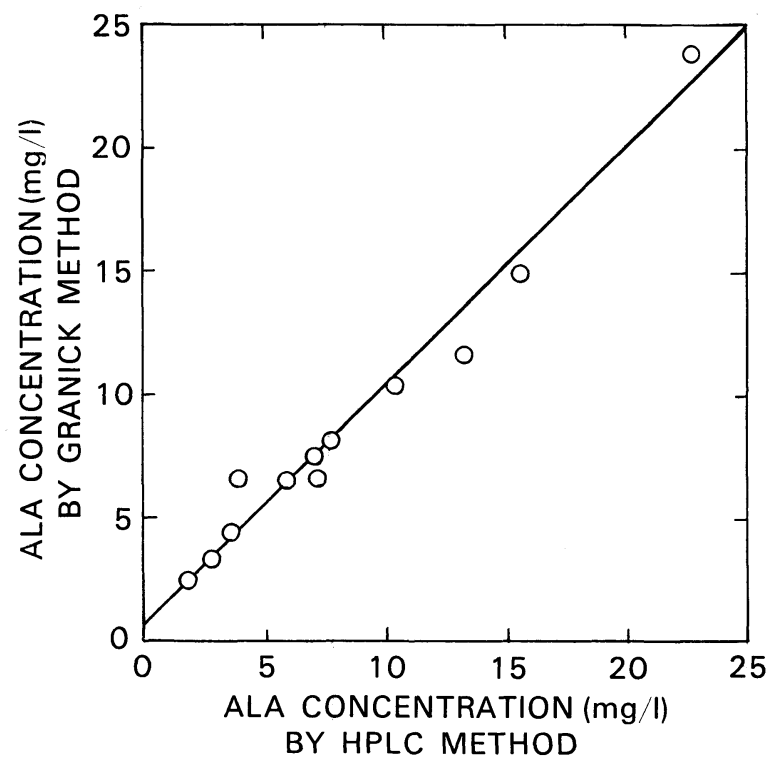

Fig. 3. Correlation between urinary ALA concentration by HPLC and that by colorimetry.

ALA concentrations in the urine of workers exposed to lead were determined both by the present HPLC method and by colorimetry (Mauzerall and Granick, 1956). A linear relationship was obtained between the ALA concentration by HPLC and that obtained by colorimetry (Fig. 3). The regression equation was $\mathrm{y}=0.79+0.95 \mathrm{x}$ (correlation coefficient $=0.99$ ), where $\mathrm{y}=$ ALA concentration determined by colorimetry, and $\mathrm{x}=$ ALA concentration determined by HPLC. 

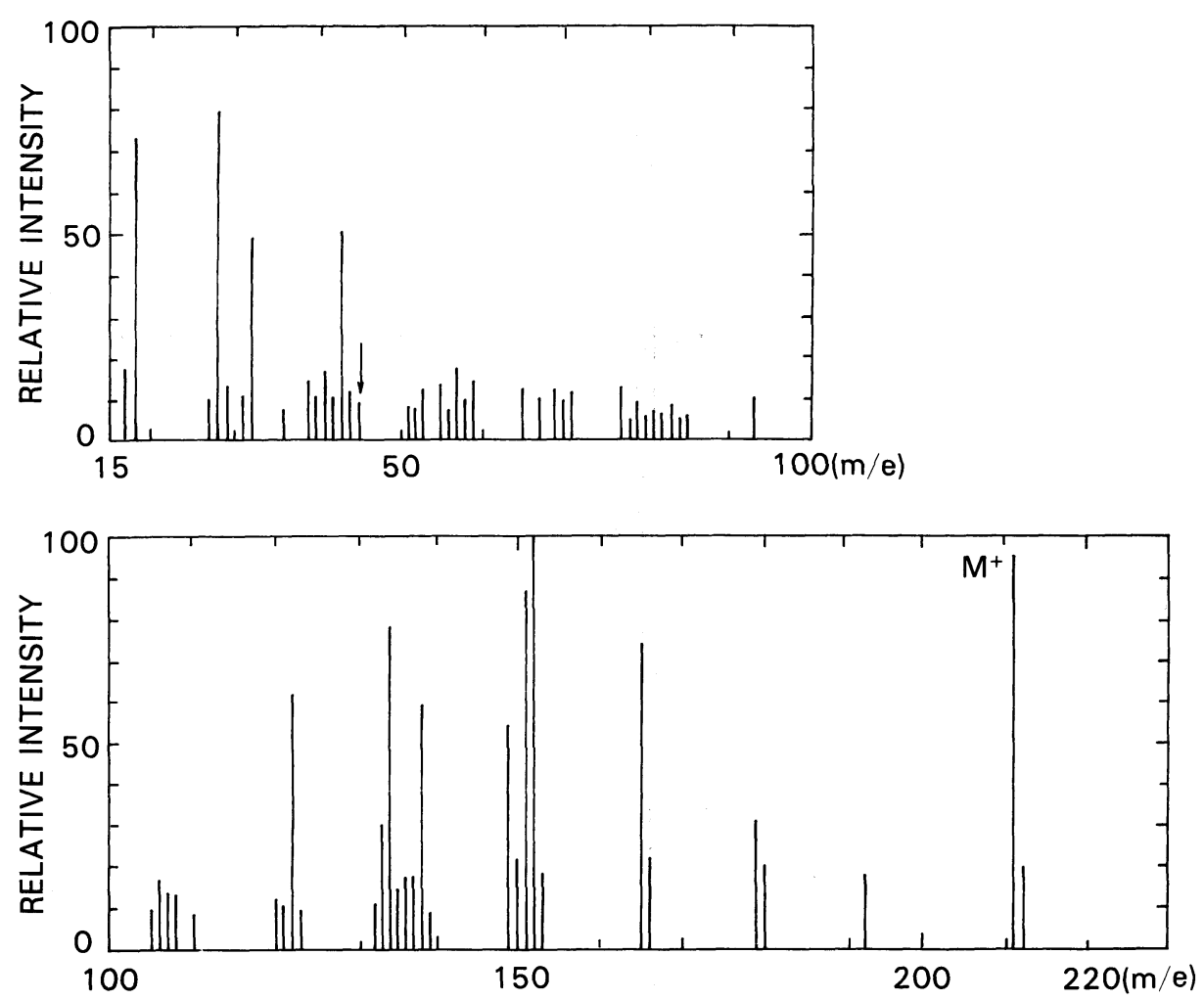

Fig. 4. Mass spectra of ALA pyrrole produced by condensation of ALA with methyl acetoacetate.

Estimated structures of fragment peaks are written in parentheses as follows; $\mathrm{m} / \mathrm{e}$, 28(CO), 43( $\left.\mathrm{CH}_{3} \mathrm{CO}\right), 45(\mathrm{COOH}), 138\left(\mathrm{M}^{+}-\mathrm{CH}_{2} \mathrm{CH}_{2} \mathrm{COOH}\right), 152\left(\mathrm{M}^{+-} \mathrm{CH}_{3} \mathrm{COO}\right), 165\left(\mathrm{M}^{+-}\right.$ $\mathrm{COOH}, \mathrm{H}), 179\left(\mathrm{M}^{+}-\mathrm{CH}_{3} \mathrm{OH}\right)$ and $193\left(\mathrm{M}^{+-} \mathrm{H}_{2} \mathrm{O}\right)$.

At higher concentrations of ALA, the levels determined by the two methods were similar to each other. However, at lower concentrations, the levels obtained by colorimetry were higher than those obtained by HPLC, suggesting that the latter method was more specific for urinary ALA than the former.

Structure of ALA Pyrrole

The structure of ALA pyrrole was considered to be 2-methyl-3-carbomethoxy4-(3-propionic acid) pyrrole, produced by condensation of the amino radical of ALA with the keto radical of methylacetoacetate. For identification of this compound, standard synthetic ALA pyrrole, showing a single peak by HPLC, was applied to the mass spectrometer.

The spectrogram recorded is shown in Fig. 4. Fragment peak at $\mathrm{m} / \mathrm{e}=43$ $\left(\mathrm{CH}_{3} \mathrm{CO}\right)$ and $\mathrm{m} / \mathrm{e}=45(\mathrm{COOH})$ in the mass spectra suggested that the pyrrole nucleus has a fatty acid structure as its side chain.

Prominent peaks at $\mathrm{m} / \mathrm{e}=138\left(\mathrm{M}^{+}-\mathrm{CH}_{2} \mathrm{CH}_{2} \mathrm{COOH}\right)$ and $\mathrm{m} / \mathrm{e}=152\left(\mathrm{M}^{+}-\right.$ 
$\mathrm{CH}_{3} \mathrm{COO}$ ) indicated that the two groups " $\mathrm{CH}_{2} \mathrm{CH}_{2} \mathrm{COOH}$ " and " $\mathrm{CH}_{3} \mathrm{COO}$ " are attached as the side chains of the pyrrole nucleus. Eventually, the mass spectrum having a $\mathrm{m} / \mathrm{e}$ for $\mathrm{M}^{+}$of 211 indicated that 2-methyl-3-carbomethoxy-4(3-propionic acid) was the possible structure of ALA pyrrole.

Advantage of This HPLC Method

The method described here is simpler than the other assay methods for urinary ALA determination, because it allows the extraction and colorimetric procedures to be omitted. The present method is specific to ALA because ALA pyrrole identified by mass spectroscopy shows a single peak by HPLC. The ALA concentration obtained by this method was less than that obtained by colorimetry, ${ }^{4}$ suggesting that the latter method also detects other pyrroles such as amino acetone pyrrole which is produced with methylacetoacetate, and HPLC measures sole ALA pyrrole.

\section{REFERENCES}

1) Cramer, K. and Slender, S. (1965). Studies in lead poisoning. Comparison between different laboratory tests, Brit. J. Ind. Med., 22, 311.

2) Mazuerall, D. and Granick, S. (1956). The occurrence and determination of deltaaminolevulinic acid and porphobilinogen in urine, J. Biol. Chem., 219, 435.

3) Wada, O., Toyokawa, K., Urata, G., Yano, Y. and Nakano, K. (1969). A simple method for the quantitative analysis of urinary delta-aminolevulinic acid to evaluate lead absorption, Br. J. Ind. Med., 26, 240.

4) Tomokuni, K. and Ogata, M. (1972). Simple method for determination of urinary delta-aminolevulinic acid as an index of exposure, Clin. Chem., 18, 1534.

5) Tomokuni, K., Hasegawa, N. and Sugawara, E. (1986). Improved method for the determination of urinary delta-aminolevulinic acid in lead workers, Jpn. J. Ind. Health, 28, 114 .

Department of Public Health, Okayama University Medical School

Masana OGATA

and

2-5-1, Shikata-cho,

700 Okayama, Japain
Toyohiro TAGUCHI 